\title{
‘BAD’ TRASH: PROBLEMATISING WASTE IN BLANTYRE, MALAWI
}

\author{
Marc Kalina ${ }^{1, *}$ and Elizabeth Tilley ${ }^{2}$ \\ ${ }^{1}$ University of KwaZulu-Natal, 238 Mazisi Kunene Rd Glenwood, Durban, KwaZulu-Natal 4041, South Africa \\ 2 University of Malawi, The Polytechnic - Environmental Health, Private Bag 303, Blantyre 0003, Malawi
}

Article Info:
Received:
8 January 2020
Revised:
30 March 2020
Accepted:
15 April 2020
Available online:
24 July 2020
Keywords:
Dumpsite
Foucault
Informal waste pickers
Africa

\section{INTRODUCTION}

This place has changed. In the past they used to dump good things here, such as plastic sheeting and paint, but now they have stopped bringing those things... They should dump good trash, not just the waste items they are dumping nowadays, so that when we collect [the items that we want] we will somehow be happy?

Waste is a universal facet of human existence. A used paper cup, a polystyrene takeout container, or a discarded plastic shopping bag, these items and many more, make up the collective detritus of our civilisation, which we are constantly forced to confront and manage. However, as Kennedy (2007) notes in his book An Ontology of Trash, most of our refuse, aside from perhaps a scuff or a bit of dirt marring its surface, undergoes little qualitative change in its transition from desirable commodity to something that must be separated from society, hid, or destroyed. As Kennedy (2007, p. xv) wisely asks, "what does the brief act of consumption involve that could cause such powerful ontological effects?" However, as the quote at the top of the page suggests, spoken by an informal waste picker at
Mzedi Dump Site (the only municipal-run waste management facility in Blantyre, Malawi), within the Global South, and particularly amongst its poor, ontological distinctions between commodity and 'waste' are less rigid, with objects often living multiple lives of utility; even, as the quote illustrates, for the small percentage of domestic waste that ultimately reaches a dump site. Moreover, as those who dwell within one of Latin America, Asia, or Africa's emerging cities can attest, waste, in the form of litter, is part and parcel of the urban fabric, an element of urban life that must be constantly negotiated, utilised, or, more likely, ignored by city dwellers.

Although Kennedy's work speaks more to why, specifically, a late-stage capitalist West wastes, and the ontological implications of this relationship to Being that this wastage entails, he makes a useful ontological distinction between 'waste' and 'trash' that resonates more broadly. To Kennedy (2007), 'waste' is a subjective notion: beauty is in the eye of the beholder. With 'waste', devaluation is relative and personal: one individual's trash may be another's treasure. 'Waste' has value to the right person who knows how to harness or appreciate it. As Reno (2015, p. 559) articulates, nothing is 'waste' in general, only in particular. 'Trash' 
however, lacks this nuance. If 'waste' results from a relative, subjective devaluation, then 'trash' is the product of unconditional, absolute devaluation (Kennedy, 2007, p. 10). 'Trash' holds no value, and no longer has a place within society. Although the discursive elements of this distinction may not translate neatly from English, to say, Chichewa, the predominant language of Southern Malawi, or one of many other numerous languages spoken throughout the Global South, the divergence allows for more flexible conceptualisations of the journey an item takes from usable commodity to unusable castaway within these under-investigated contexts ${ }^{2}$. However, once an object is understood as 'trash' within Kennedy's conceptualisation of the term, at what point does it become an issue that must be dealt with- either removed, destroyed, or avoided altogether? In other words, for individuals within the Global South, when does 'trash' become a problem, how do these processes of problem formation occur, and how can they be conceptualised?

The purpose of this article is to explore these processes of problem formation through the experiences of two separate, but often interdependent, communities within Blantyre, Malawi: informal waste pickers who salvage saleable waste items for their livelihood within Mzedi dump and local subsistence farmers who grow and harvest maize on and along the margins of the same site. Drawing on extensive qualitative, ethnographic fieldwork within each group, the article explores, how for differently placed people negotiating the same space and confronting similar 'waste' hazards, problem formation remains personal and contextual, informing how each individual navigates and utilises Mzedi for their own purposes. Moreover, responding to a lack of critical social theory to conceptualise these processes of problem formation, this study adapts Michel Foucault's notion of problematisation, first invoked by Foucault as a pathway for critical analysis of the city. Foucault's notion of problematisation is useful a lens through which to observe processes of problem formation because it emphasises the connection between problems and the individuals they affect. Foucault's writings have been applied extensively within the social sciences to understand the process of problem formation at a societal level, particularly as a mode of critique within urban studies. However, this article considers more recent contributions by Bacchi (2015), Barnett and Bridge (2016), and Oberg (2019) which attempt to operationalise the term as an analytical tool to understand processes of problem formation amongst disparate urban contexts and at a personal, rather than solely societal, level. Our findings suggest that Foucault's concept of problematisation is a useful lens through which to interpret the ways in which different individuals 'problematise' the various 'waste' and 'trash' items within Mzedi. Foucault's conception of problematisation, and subsequent elaborations on the notion, allow for a situational analysis of the formation of problems (Barnett \& Bridge, 2016). As with individual ontological formations around 'waste' objects, personal conceptions of problems do not exist, as Oberg (2019) identified, independently from the people they affect, rather, these conceptions are continually shaped and reshaped through human agency, need, and livelihood practices. Understanding these processes of problem formation, through which differently placed individuals problematise 'trash', and the degree to which these problematisations are shaped by culture, values, and other contextual factors, has important ramifications for the adoption of appropriate waste management or circular economy strategies. This investigation is particularly important within the context of Malawi, and the Global South more broadly, and should inform a more nuanced, and less normatively Western waste management studies discourse.

\section{THINKING PHILOSOPHICALLY ABOUT WA- STE}

How does an object, once a desirable commodity, become 'waste', and how does this process occur within different contexts, continents or ontological formations? Despite the ubiquity of waste within our modern existence, and since Mary Douglas' (1966) famous characterisation of dirt or waste as "matter out of place," there have been few philosophical deconstructions of the phemonological and ontological links that bind humans and waste, particularly contextualised within Africa or the Global South. Nonetheless, with the recent emergence of Discard Studies ${ }^{3}$, a small but growing voice within broader waste management academic discourse, there has been increased interest in the wider role of society and culture in defining and structuring attitudes towards, and behaviours around, waste, however that concept may be construed. This section seeks to provide a brief overview of contemporary philosophical, ontological, and epistemological deconstructions ${ }^{4}$ of waste in order to contextualise the recent developments taking place within the discipline and to situate this piece both ontologically and conceptually.

Kennedy's (2007) writings predate the more recent interpretive turn within waste management discourse driven by Discard Studies. Speaking to, yet departing from Heidegger's ontological project, Kennedy interrogates the historical phenomenon of disposable commodities. To Kennedy (2007) trash represents the collapse of the ontological structure of human Being: a failure of humanity at a fundamental level. Waste reflects our own short-comings, our failure to preserve the value originally invested in objectsall we can do as machine-minded, uncaring consumers is purchase, consume, trash, and purchase anew (Kennedy, 2007, pp. 181-182). Both Hird (2012) and Spelman (2011) speak to Kennedy's conceptualisations of wastage in order to provide epistemological commentary on 'knowing' waste, rooted in their respective disciplines, and invite the reader to interrogate their own personal understandings of waste. Likewise, Moore (2012) highlights the ways in which different views of what waste 'is', are productive of many forms of scholarship that have the potential to disturb certain taken-for-granted ideas about values, politics, and socio-spatial relationships. Moore proposes that that waste be thought of as parallax object-not as a binary good or bad, but as something that 'disturbs the smooth running of things'. Reno (2014) speaks directly to Douglas' aphorism, attempting to reframe conceptualisations of 'waste' 
without dirt as a starting point. To Reno (2014), it is worth considering how waste is interpreted from trans-species perspectives, and how these interpretations serve to mediate transactions between living beings. Focusing on faeces, Reno argues that objects, commonly considered 'waste' are not arbitrarily classified, but purposefully assigned, and thus symptomatic of life's spatio-temporal continuation. In other words, waste is the sign of the living; waste, in this instance, faeces, as the evidence of the lifeform's continued existence. Though Reno does not speak to the ultimate item of waste we leave behind when we exit that existence, our corpses, it is a creative reconceptualisation, nonetheless.

To Kennedy, trash and wastage represent the ontological collapse of our human modern civilisation. However, to Viney (2014) an interest in trash and waste is rather more ageless, representing one of the central aspects of human existence. Drawing on literary, artistic, and socio-cultural tradition from throughout history, Viney (2014) argues that the concept, like the thing, is socially constructed within a given time and space, and that our momentary relations with such items are managed and acknowledged in nuanced ways. Focusing on one specific waste stream, Van Bemmel and Parizeau (2019) examine the materiality of food waste. They point out that often, the lines that delineate edible food from waste are blurred. Moreover, their study suggests that socio-cultural norms, such as aesthetic standards, and systematic factors, such as temperature regimes or best before dates, are central determinants to food making the ontological transition to waste (Van Bemmel \& Parizeau, 2019). This transformation from food to waste is not unidirectional however, as Van Bemmel and Parizeau (2019) describe instances of 'rehabilitation', where rejected produce is transformed into higher value processed products or past-date grocery items are scavenged from dumpsters ('dumpster diving'), recalling Kennedy's (2007) more subjective and relational deconstruction of 'waste'. Next, Ablitt and Smith (2019) examine the 'practical objectivity' of objects as they are handled through the everyday work of street cleaners in Gibraltar. Also starting from Douglas' aphorism on 'dirt', Ablitt and Smith (2019) reject her characterisations of the term as a basis for broad theorisation of social structure and culture, instead speaking to the ways in which 'dirt' and 'waste' are locally and practically assembled and negotiated through quotidian interactions. Their findings suggest that on the streets, 'waste' is seeable through a relational contexture of visually available elements within a given street scene (Ablitt \& Smith, 2019). More interestingly however, they demonstrate a possibility for certain objects to also be 'seen' as bound to associated categories of people, a conclusion that deserves further investigation within different contexts.

Finally, a number of contemporary reflections on 'waste' have attempted to break free from the traditional western and euro-centric outlook of waste management discourse in order to include valuable perspectives from the Global South, as well as centres of informality. For instance Oloko (2018) examines print media reports in Nigeria to examine the ways in which 'dirt', 'waste', and 'garbage' function as relational and socially constructed concepts within in- tersecting sanitation and social contexts. Oloko's (2018) analysis reveals that media coverage on issues of waste or sanitation often carries discursive undertones of power, in which emotive terms related to waste are often used to justify the exclusion of marginalised groups or individuals, such as sex workers or the poor, from general society. He concludes that in this context waste' and 'garbage' are not merely relational objects, but rather evocative terminologies adopted by the healthy and powerful to mark out a space of physical, moral and political non-belonging inhabited by the weak or marginalised (Oloko, 2018). Writing about the Eastern Himalayas, Wang (2019) examines how differing interpretations of 'trash' adds to the complexity of relations between Han Chinese and indigenous Tibetans. According to Wang (2019), Tibetan cultural practices include a number of acts construed by Han Chinese as littering, creating disputes between the two groups over what is sacred and what is trash. Wang (2019) argues, however, that these 'littered' objects should not be considered as such, rather they should be conceptualised as people, as their purpose is to mediate the reciprocal relationship between humans and the environment-conclusions, that speak to the need for looser and more contextually appropriate conceptualisations of personhood within waste management practices. Lastly, a number of studies have explored the reconceptulisation of waste as a resource through the eyes and everyday experiences of waste pickers. To these individuals 'waste' is a relational concept, both a hazard and an opportunity. Within the waste picker community, recyclables are symbols of accumulation and individual ability; material testimonials to hard work and business networks (Ka-Ming \& Jieying, 2019). Yet, as Gutberlet and Uddin (2017) describe, waste, even household waste, can pose significant risks to those who handle it. Moreover, reflecting Ablitt and Smith's (2019) findings, which suggest that certain objects can be 'seen' as bound to certain categories of people, Ka-Ming and Jieying (2019) show that amongst waste pickers different types of waste can be powerful signifiers to identity and internal status, with poor migrants being associated with general rubbish, but more established and visibly successful individuals monopolising trade in more lucrative waste streams. These previously cited contributions suggest that waste is often a fluid concept within the Global South, and that waste management studies discourses are embracing more flexible constructions of waste and society, however there remains significant scope for further philosophical, ontological, and epistemological deconstructions within these contexts.

\section{PROBLEM FORMATION AND WASTE PRO- BLEMATISATIONS}

Once an object is considered trash, what then? Many a city street, in both the Global North and the Global South, is littered with objects that most city dwellers would consider 'trash' in Kennedy's reckoning of the term, yet for the most part, they are ignored, with residents content to pass them by, or at most, kick them out of the way. An occasional conscientious passer-by may pick up an empty bottle and deposit it in the bin, but would they do the same for 
chewed gum, or for leaf litter? Either these objects, individually or collectively, are not construed by the passer-by as a problem, or as not enough of a problem do anything about. But what if there is broken glass on the sidewalk? Or a used hypodermic needle? Or perhaps there are also children playing nearby? Do these objects now become more than nuisances that can be ignored, transforming into problems that must be dealt with or actively avoided? Similarly, for the individual accustomed to litter on their streets, how much is too much, where a nuisance is transformed into a community issue, which becomes the object of collective or political action? When and how do these processes of problem formation occur, and to what degree are they personal and/or socially constructed. In other words, how do individuals problematise waste, and how do these individual problematisations form?

Despite the richness of recent philosophical reflections, few, including the works mentioned previously, have spoken directly to these processes of problem formation. This observation is not intended as a critique, however, as their contributions are valuable in their own right, and open the door for further interrogation of the phenomenological links between individuals, society, and waste. As Barnett and Bridge (2016) note, the formation of problems is, of course, a longstanding concern within the social sciences. Emphasis has historically been on matching problems with policy, and notable examples would include Bacchi's (2009, $2012,2016)$ methodological approaches for analysing how problems are represented in policies and Turnbull's (2006) critique of public policy and problem solving. These pieces however, focus on problem formation and problem soliving (e.g. through public policy approaches) at a societal level, not at the level of the individual going through their quotidian existence. Likewise, regarding waste, Gregson and Crang (2010) argue that much of the work that does address problem formation does so at the level of the categorical (see (Davoudi, 2000, 2009; Hillier, 2009; Petts \& Niemeyer, 2004). Rather than opening out into its ontological politics, waste is problematised in ways that can be neatly categorised within policy frameworks rather than through messy depictions of social construction (Gregson \& Crang, 2010). These contributions are, of course, deeply contextualised within the writings and social-constructionist traditions of Michel Foucault, specifically his notion of 'problematisation' as a means for understanding processes of problem formation (Barnett \& Bridge, 2016). To Foucault, problematisation is the process through which inert, apolitical, and fixed objects (such as waste) transform into sets of fluid, conditional, political relations (Foucault, 1984). According to Oberg (2019) the power of Foucault's view on problem formation, or 'problematisations', is its characterisation of them as results of particular social relations, contingent on human practice, rather than inevitabilities. Until recently, Foucault's notion of problematisation had primarily been utilised as a means for critique within urban studies, at a societal level. However, recent contributions by Bacchi (2015), Barnett and Bridge (2016), and Oberg (2019) have demonstrated how the concept can be utilised as an analytical tool to understand processes of problem formation that occur within the individual, and how these processes may be applied in regards to waste.

Reflecting on the importance of approaching the concepts of urban inquiry problematically, Barnett and Bridge (2016) press the modern relevance of Foucault's conceptions of problematisations as part of thinking problematically about urban issues. Foucault is best known for his theories on power, and specifically, state power. As Barnett and Bridge (2016) describe, Foucault's ideas have often served as frames of analysis for the ways in which we engage critically with the city. However, to Barnett and Bridge (2016), Foucault is not merely a theorist of critique, as he has been most often characterised, but also a theorist of action. This emphasis translates into their interpretation of problematisation, which they, echoing Foucault's (1984) own characterisations, place on action as a 'responsive disposition to difficult situations' (Barnett \& Bridge, 2016, p. 1189). Moreover, as Barnett and Bridge (2016) note, Foucault, during his own reflections on the subject, was insistent that problematisations are not simply 'an arrangement of representations', rather, scrutinising problematisations involves two paths by "which one tries to see how the different solutions to a problem have been constructed; but also how these solutions result from a specific form of problematisation" (Foucault, 1984, pp. 389-390). Their view is more democratic than Foucault's however, as Barnett and Bridge (2016) start from a presumption that the act of problematisation is a more broadly lived reality of urban life. To them, it is not a refined academic skill, but a basic feature of engaged action and conscious decision-making across any number of issues or lifestyles (Barnett \& Bridge, 2016, p. 1201).

Helpfully, Barnett and Bridge (2016) distinguish between two aspects of use for Foucault's notion of problematisation commonly utilised within the social sciences: its forms as both a noun and a verb. First, problematisation, the noun, characterises the problematisation as an object of analysis. As Barnett and Bridge (2016) describe, it is the label attached to the process by which, for example, various lifestyles, livelihoods, or spatial arrangements are questioned and become the target for motivated adjustments and transformations. The second aspect, problematisation, or problematise, the verb, refers instead to a method of analysis, most commonly utilised by researchers within urban studies. Within this sense of the term, according to Barnett and Bridge's interpretation (2016, p. 1191), the purpose of critical analysis is to question understandings, relationships, and settlements that were previously takenfor-granted. Bacchi (2015) draws a clearer distinction between the usages. To Bacchi (2015), 'problematise' (the verb) tends to be used to describe what individuals or governments do in the face of problems, while the noun (i.e. problematisations), generally refers to the outcomes of problematisations, either in the way in which problems are framed, or governmental problematizing processes. Bacchi (2015) further clarifies that the verb form can be used in two ways. First, to describe a form of critical analysis, such as described by Barnett and Bridge (2016), and commonly utilised within the social sciences when questioning or interrogating a specific issue (Bacchi, 2015, 2016). The second form, however, is more pertinent to the objectives 
of this study: referring to the ways in which individuals put an issue, object, etc. forward, or designate something, as problematic-"that, is to give a shape to something as a 'problem"' (Bacchi, 2015, p. 3).

Within Barnet and Bridge's (2016) reading of Foucault, problematisations primarily occur at the societal level: inside, in concert with, or in opposition to the state. Bacchi (2015), likewise, considers how governing involves problematizing, shaping issues as 'problems'. However, Bacchi (2015) also extends these processes of problem formation to the individual-how people (policy makers, social scientists, but also regular citizens) internally and phemonologically examine, consider, interpret, and then 'frame' an issue as potentially problematic. Neither speak explicitly to the ways in which individuals might problematise specific objects, or groups of objects, such as waste. Oberg (2019), however, broadens the utility of the term, shifting the scope of analysis from problematisations around a given issue, to understanding how individuals problematise certain experiences, in this instance open defecation in urban India. Her analysis found that nearly all actors, including a broader range of stakeholders within Agra, problematise open defecation for various reasons, viewing it as inconvenient, dangerous, a source of disease, undignified, polluting, and/ or primitive. However, some problematisations, such as its inconvenience, were limited to only certain actors, while others emphasise problematisations, such as the risk of disease, that others do not consider as a problem (Oberg, 2019). To Oberg (2019), the value in using the concept of problematisation as an analytical tool is that it allowed for the full range of defecatory experiences in a given context to emerge. As she notes, there is value in simply recognising the existence of all problematisations. Accounting for the full spectrum of experiences "gives voice to subordinated problematisations and the groups enacting them, answering the normative imperative to be more inclusive" (Oberg, 2019 , p. 389). A focus on problematisations allows for hidden factors to emerge within decision making and problem formation processes, while considering respondents as rational decision-makers. Most importantly, to Oberg (2019), exploring the full range of problematisations counters dominant problematisations by presenting other, more inclusive, alternatives. In an attempt to build on Oberg, Bacchi, and Barnett and Bridge's broader conceptualisations of Foucault's problematisations as an analytical lens through which to interpret process of problem formation, the purpose of this work is to examine how individuals problematise waste objects within their daily lives. Specifically, we seek to understand, how two groups, who live and work within or around the boundaries of Mzedi Dump Site, in Blantyre, Malawi, problematise the often hazardous waste fractions they encounter daily, and how these problematisations are shaped through their interactions with each other and the broader community, beyond the dump.

\section{MZEDI DUMPSITE}

This study draws on extensive qualitative, participatory fieldwork in and around Mzedi Dump Site, Blantyre, Malawi's only municipal-run waste management facility.
A space of diverse livelihoods and hazards, Mzedi represents both opportunity and hardship for the more than 100 informal waste pickers (IWPs) who work there, as well as for the scattered communities existing on its margins. Cut like a gash from the rolling peri-urban patchwork of homes, maize fields, and shops which hug the main M3 Highway to Zomba, Mzedi is located approximately 12 kilometres northeast of central Blantyre, just beyond the fringes of the sprawling Kachere slum settlement, and symbolically dividing the urban sprawl of the city from the agricultural landscapes of rural Malawi. The site dates back to the mid1990s, when the Blantyre City Council (BCC) ${ }^{5}$, purchased the land on which Mzedi now sits from the Imperial Tobacco Group (ITG), and through minimal excavation transformed a shallow valley into a dump site. Nonetheless, as Kalina et al. (2019), describe, land tenure around Mzedi remains complicated. Although the BCC owns the majority of the land surrounding Mzedi, villagers from nearby Moto Village (Figure 1) have historically maintained the de facto right to use the space for agricultural purposes-a right the city has not actively contested ${ }^{6}$. However, the city has always maintained that this arrangement is temporary, and could be altered, should Mzedi be expanded or developed. As Kalina et al. (2019) describe, the attitude is rooted in the argument that the dumpsite pre-dated the intensive cultivation of the land, a narrative contested by local villagers, who consider the dump site an imposition on agricultural land traditionally considered theirs. This historical connection to the space is amplified by acute land pressure in the area-agricultural plots in Malawi are generational, and Mzedi is set within plots that, according to residents of Moto Village, have been allocated to families for generations. As a result, planting elsewhere is not an option, as alternative land is either not available, or is too distant to be readily accessible (Kalina et al., 2019). Consequently, Mzedi, despite being a dump, remains the site of intensive seasonal agricultural production, with many residents of Moto Village maintaining their traditional plots within and along the blurred edges of the site (Figure 2), to plant maize, as well as an assortment of other crops such as melons, tomatoes, and gourds. During the height of the growing season the site is lost in a sea of maize, as every piece of adjacent, farmable land is utilised.

The dumpsite itself has been minimally engineered. Being set in a natural valley, little excavation was required, and the bottom was not lined prior to commissioning. Construction has been limited to an earthen berm, erected along the southeastern edge of the site, and intended to protect a nearby seasonal watercourse, which passes through Moto Village, from leaching (Figure 1). This berm has evidently proven ineffective, however, as surface water tests, taken from the stream at points adjacent to Moto Village revealed severe biological and physical contamination, as well as unsafe levels of nitrates, copper $(\mathrm{Cu})$, and lead $(\mathrm{Pb})^{7,8}$ (SOFET, 2016). Opened with an expected operational life of twenty years (in the mid-1990s), Mzedi is now well past its intended lifespan, and has deteriorated considerably in recent years. The site, once forested, is now exposed, with no fixed boundaries separating dumping grounds from adjacent agricultural land. Furthermore, the access road, once 


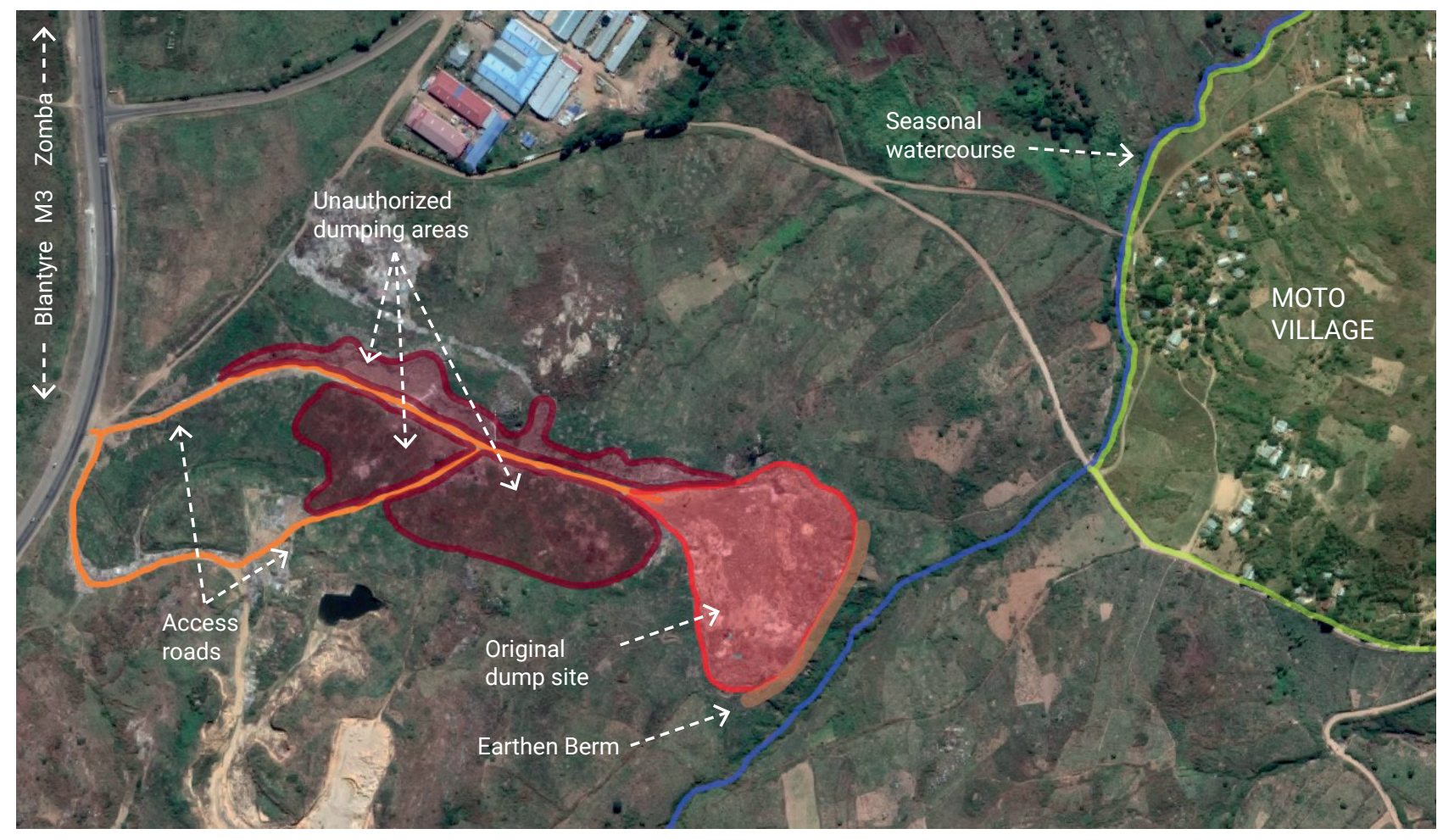

FIGURE 1: Mzedi Dumpsite and Moto Village.

paved, has become deeply rutted, and is often impassable, especially during the rainy season. As a result, unauthorised dumping has proliferated along the margins along the main site, with the access road itself becoming a secondary dumping ground, as trucks illegally unload along it when the main site becomes inaccessible (Figure 2). Unfortunately, this deterioration is expected to continue, as the city lacks both the funds and the heavy equipment to clear the road or conduct necessary upgrades to the site. Looking forward, city officials pin their hopes on the construction of a new

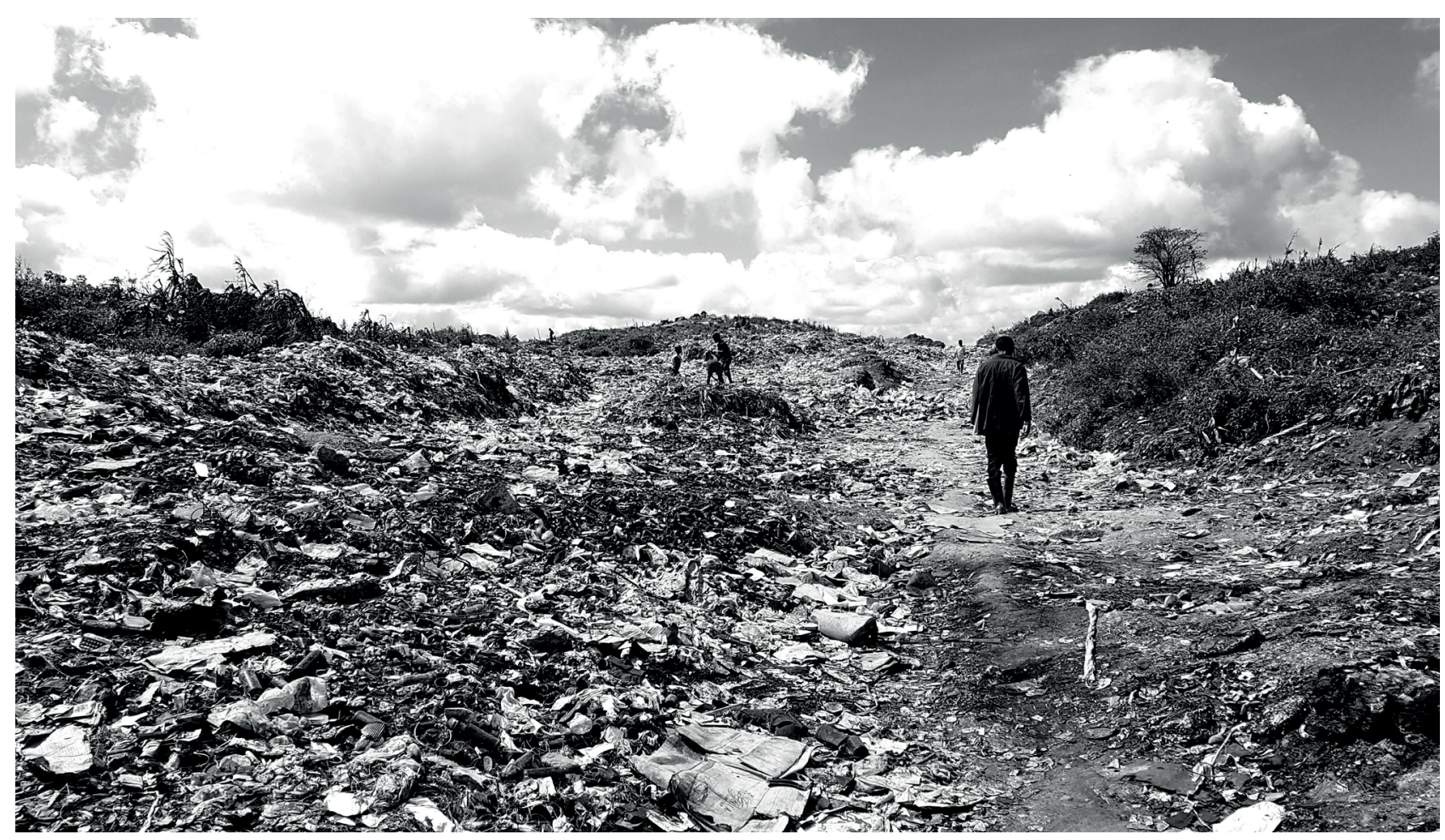

FIGURE 2: Primary access road to Mzedi dumpsite; maize and unauthorized trash dumping are visible along the sides (Kalina, 2019). 
site that will improve upon many of Mzedi's failings, however, such an intervention is unlikely to materialise, as waste management services within Blantyre are conducted under extreme financial limitations, necessitating Mzedi's continued use (Kalina et al., 2019).

Prior to Mzedi's construction, dumping within Blantyre was neither formalised nor centralised, with the city utilising a variety of scattered, local, and temporary dumping grounds, typically disused quarries or abandoned construction sites, on an ad-hoc basis when necessary. Nontheless, despite the BCC centralising waste management disposal at Mzedi, the site still only contains a fraction of the waste produced within Blantyre, as waste collection services remain extremely limited. According to Ndau and Tilley (2018), the City of Blantyre only offers household waste collection within a limited number of 'formal' neighbourhoods, servicing only about $20 \%$ of the population. For the rest, the BCC maintains 43 skips (of around $7 \mathrm{~m}^{3}$ ) strategically placed at public spaces throughout the city (such as markets, hospitals, etc.), which are rotationally collected and dumped at Mzedi. Furthermore, individuals and private businesses may also purchase permits to dump, and most of Blantyre's manufacturing industries have purchased the right to dump at the site. Unfortunately, the character of the waste currently stored within Mzedi is unknown. The city maintains little control over the types of waste being dumped, as the permit system is predominantly concerned with regulating the quantity, not the quality of deposited waste. The BCC has placed restrictions around the dumping of certain hazardous wastes, such as medical waste, however compliance with these restrictions is largely voluntary, and on-site inspection of deliveries is cursory or ab- sent. Furthermore, unauthorized or unpermitted dumping is common, while hazardous waste is often mixed within general waste ${ }^{9}$. Consequently, even the BCC has a poor understanding of the amount of hazardous waste that may be present at Mzedi, and sightings of hazardous waste, such as chemicals or batteries, and medical waste, including medicines, needles, and even body parts, are common ${ }^{10}$.

Despite these hazards, more than 100 informal waste pickers (IWPs) work within Mzedi, gathering specific waste items to resell or reuse within their own households. Both the maize growers and IWPs are interrelated, as many IWPs live in Moto Village and also plant maize within and around Mzedi. The IWPs have suffered from the physical deterioration of the site, with the deforestation depriving them of shade and firewood, while the degradation of the access roads, and the resultant unauthorised dumping, has decentralised waste storage beyond the original dump site (Figure 1), making it more difficult for IWPs to quickly access and pick new deliveries (Figure 3) ${ }^{11}$. Moreover, other infrastructure, such as signage and running water, which the IWPs used to benefit from, is now missing or inoperable ${ }^{12}$. Nonetheless, the BCC maintains an uneasy, but generally indifferent relationship with the IWPs, embodied within the person and function of the dump supervisor, who is primarily responsible for ensuring compliance with the permit system, but also plays an important mediation role between the city and those individuals working and living around Mzedi.

\section{METHODOLOGY}

This study was conducted in tandem with Kalina et al. (2019), which sought to understand both the real and per-

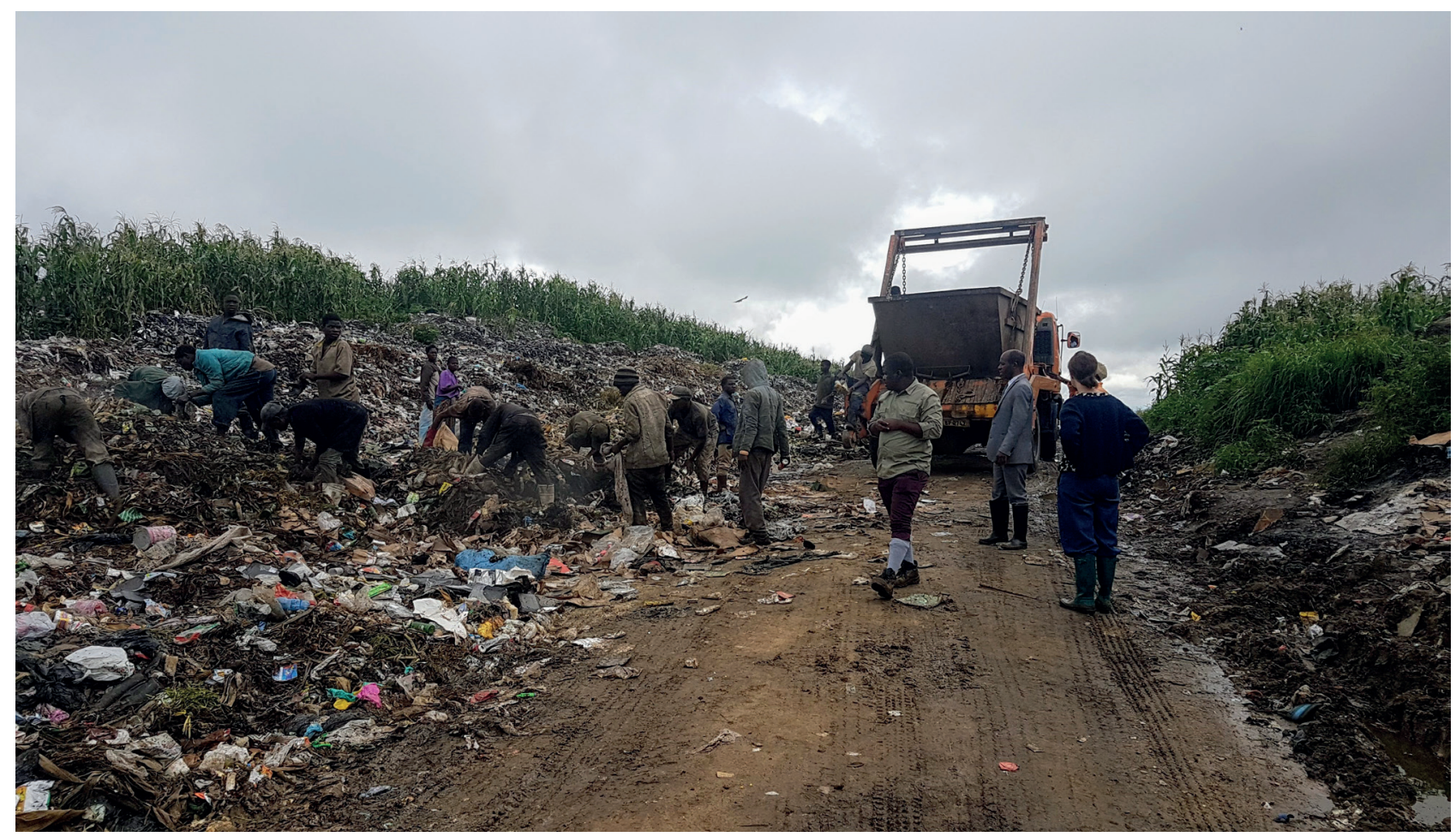

FIGURE 3: IWPs Access Waste Dumped Alongside the Access Road (Kalina, 2019). 
ceived dangers of agricultural production at Mzedi through interviewers with growers as well as laboratory testing for heavy metals within purposively sampled maize, soil, and water samples. Results suggested that agricultural production at Mzedi is reasonably safe, with no samples showing hazardous concentrations of potential toxins (Kalina et al., 2019). Nonetheless, the environmental hazards at the site, such as broken glass, medical waste, and potentially toxic wind blow dust, renders the work risky. Kalina et al. (2019) hint at the quotidian and complex processes of problem formation around waste undertaken by maize growers navigating Mzedi, but without the depth of analysis and theorisation that this article contributes. In contrast to Kalina et al. (2019), which utilised a mixed-methods approach, this study was purely qualitative and interpretative. Data collection consisted of 26 semi-structured interviews with relevant stakeholders associated with Mzedi, including officials from the BCC ${ }^{13}$, residents of Moto Village, maize growers, and IWPs. Respondents were chosen using both a purposive and snowballing sampling regimen (Kitchin \& Tate, 2000). Interviews ${ }^{14}$ were conducted in the local language (Chichewa), with a translator, audio recorded, and transcribed into English. Participation was voluntary, and responses were recorded anonymously ${ }^{15}$. Transcripts were coded and organised using Nvivo, and the analysis was conducted thematically(Denzin et al., 2017).

\section{FERTILE MZEDI: GLASS, SYRINGES, SMO- KE, AND MAIZE}

In Malawi, especially for the poor, summer is characterised by what is known colloquially as 'the hungry months', the gap in between the sowing and reaping of the annual maize harvest, during which long-hoarded maize stores dwindle, food costs spike, and malnutrition rises (Kalina et al., 2019). For subsistence agriculturalists planting at Mzedi, work begins in early November, with a rush to clear the land, till, and plant, before the first of the summer rains arrive. At Mzedi, however, this work is not just considered difficult, but hazardous, as the growers reported frequently encountering sharp objects, primarily shards of metal, nails, and broken glass when clearing the soil-work that is primarily done by hand. These sharp objects were clearly characterised as problems by growers: environmental hazards and occupational risks that needed to be navigated on a daily basis. Indeed, nearly every grower spoke of past injuries and cuts incurred while clearing the soil prior to planting, particularly to the hands and feet, and a cursory glance at the hands of each respondent revealed numerous and often substantial scars (Figure 4) ${ }^{16}$. Moreover, because many growers are also handling waste on a daily basis, and WASH facilities at Mzedi and in Moto Village are basic, wounds often heal poorly or become infected. Despite identifying broken glass as a persistent problem in their plots, growers generally make no effort to remove it, simply shifting it aside when preparing the soil for planting or during harvesting. These objects are clearly problematised by growers, however, most respondents implied in their comments that at Mzedi the glass was nearly as plentiful as the soil, and have essentially accepted it as one of inevitabilities of cultivating the space. Finally, although less common than the ubiquitous glass at the site, one grower reported encountering medical waste, including used syringes and other sharps when preparing the soil within his traditional plot ${ }^{17}$. These items, however, although identified as a problem by the grower, were not problematised

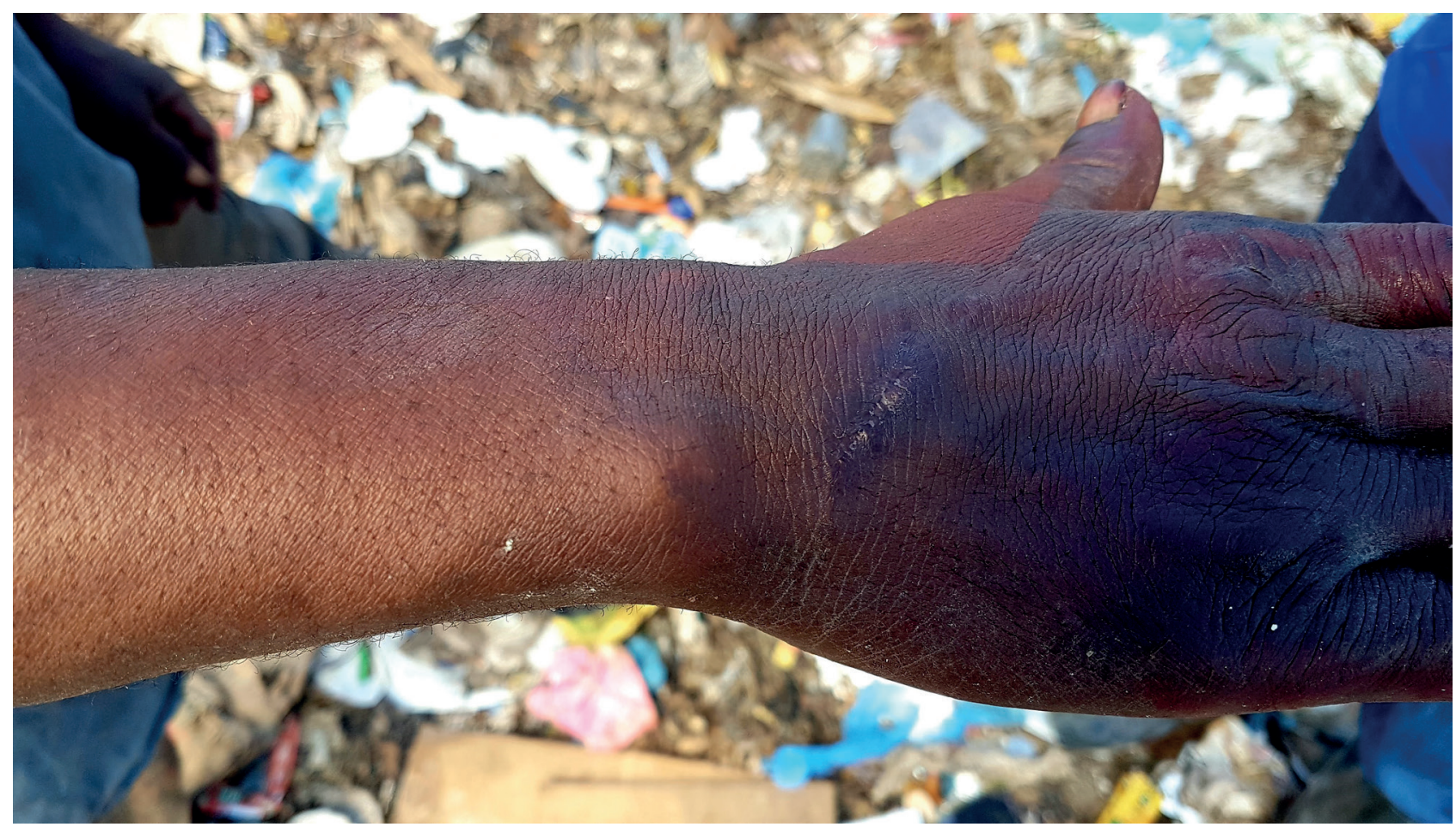

FIGURE 4: An IWP shows a scar caused by broken glass at Mzedi (Kalina, 2019). 
in relation to their potential infection risks, which were not mentioned by respondents, but in their ability to cause bodily harm.

One environmental hazard that has been clearly problematised by maize growers, on the basis of its potential health risk, is the persistent cloud of dark smoke which hangs over the site. Caused by the many small fires started by IWPs for cooking, heat, or to burn waste to extract recyclable metals, the smoke caused by these fires is particularly acute during the dry season (May-October), and they can often spread and burn uncontrolled, smouldering for weeks until a rain or until it runs out of fuel. When speaking about the smoke, growers were unable to point to a specific instance in when it made it them ill, however there was a general awareness that the air at the site was polluted and unhealthy. Many reported struggling to breathe and coughing when inhaling the smoke while in the vicinity of the site, while one grower who had been diagnosed with asthma, blamed the smoke for causing and frequently exacerbating his condition ${ }^{18}$.

In Malawi, April is the month of harvest, and at this time, in Moto Village, the daylight hours are predominantly occupied with the labours needed to harvest, process, and store the annual maize harvest ${ }^{19}$. Kalina et al. (2019) describe these daily rhythms in detail. Once ripe, the maize is not harvested immediately, but rather is left on the stalk in the field for several weeks in order to partially dry. After picking, the ears are husked and the kernels are stripped from the cob ${ }^{20}$. Bare cobs and husks are dried and burnt for household fires, while the kernels are spread on mats to dry in the sun. Once dried, seed for next year's crop is selected and saved, while the remainder is stored, crushed into maize meal on demand, and consumed throughout the year. Those growing maize in the vicinity of Mzedi dump site largely do so for subsistence purposes, consuming the bulk of what they grow within their own households. However, in good years, some reported small surpluses that they were able to sell ${ }^{21}$.

Amongst growers, there was little concern that they maize they were growing came from a dump site, and few problematised the potentially hazardous impacts ${ }^{22}$ that the waste in the site could have on their crops, and consequently, their health. One explanation for this is that, according to the majority of growers, the maize that is produced on the margins of Mzedi, and once harvested, is virtually indistinguishable, in terms of size, taste, and colour, from maize grown elsewhere, including what is available in local markets and from the Agricultural Development Marketing Corporation ${ }^{23}$ (ADMARC). For the small surpluses that can be sold, kernels from Mzedi are mixed with those from other locations, and respondents reported that their customers either were not aware that the maize they were purchasing came from the dump site or were unable to distinguish it from the other source ${ }^{24}$. One respondent, however, did note that their customers knew that the maize they were buying was grown near the dumpsite, but it did not discourage them from buying, because the product is indistinguishable from other maize ${ }^{25}$. Of the growers interviewed, only two expressed some concern that the waste stored at Mzedi may have a potentially negative impact on the maize grown there. Both expressed a belief that maize grown at the dumpsite had a tendency to rot before it is harvested, while left on the stalk to dry ${ }^{26}$. Moreover, one of the growers described the maize kernels from the dumpsite as being slightly darker in colour and having a less pleasant taste than maize grown closer to the village ${ }^{27}$. Both believed the waste stored at the dumpsite was responsible for these impacts, particularly the rotting, however they were unable to explain what types of waste may be potentially harmful, and were unable to describe what processes or waste types may be responsible for negatively impacting the maize.

To those who cultivate maize on its margins (and to a lesser extent, within) Mzedi is clearly a hazardous space (Figure 5). They have problematised its visible, environmental dangers, such as broken glass and other sharp objects, medical waste, and the persistent pall of noxious smoke, because they are tangible dangers, which have negatively affected their safety and health. For the majority of respondents, problem formation has not occurred around the dump's hidden dangers, specifically, the potential health risks of consuming maize from contaminated soil, because the threat is not visible (potentially harmful concentrations of arsenic, for instance, would be tasteless) or because growers are not aware that potentially negative health impacts are possible. Quite simply, they do not consider dumpsite-grown maize as a problem because it has not yet tangibly affected them, and when broached, the immediacies of survival and food security overshadow such nebulous concerns. However, although most growers have not problematised the relationship between the waste in Mzedi and their maize crop, it is not because they are unable to conceptualise that the former may affect the latter. Rather, and despite its hazards, the plots adjacent to Mzedi are considered attractive places to plant because they are seen as particularly fertile, a fertility that most growers attributed to the waste ${ }^{28}$. However, nobody was able to articulate what processes were responsible for positively affecting the soil or describe which types of waste may have beneficial impacts. Nonetheless, there is some awareness amongst growers that the waste stored at Mzedi may be influencing their maize in some way.

\section{7. 'WASTE', 'TRASH', PROBLEMS, AND OP- PORTUNITY}

In addition to being a site of agricultural production, Mzedi also supports the livelihood of more than 100 informal waste pickers (IWPs). Many have worked at the site since its opening, live in nearby Moto Village, and have witnessed the steady physical deterioration of the site. Although the official relationship between the IWPs and the city is antagonistic-the BCC Director of the Department of Health and Social Services described the two parties as 'enemies'-on the ground there is less tension, with a mutual toleration between city workers and IWPs, borne out of shared hardship and poor working conditions. For these IWPs, problem formation in regard to waste and Mzedi, has, like with the maize growers, largely centred on the tangible environmental health and safety risks that are a consequence of navigating a dumpsite. Likewise, broken glass was frequently 


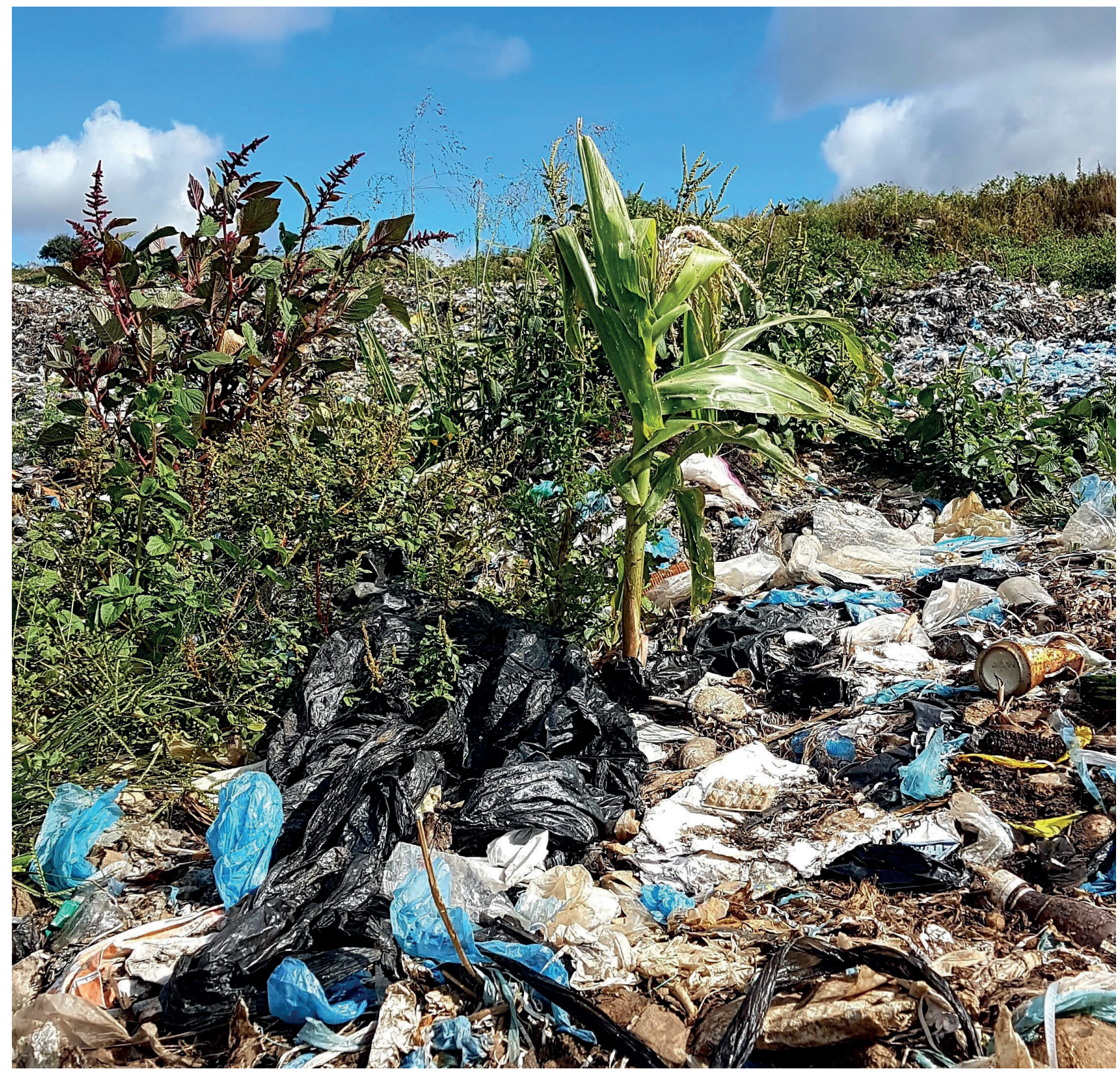

FIGURE 5: Maize plant growing near the centre of the original dumping area (Kalina, 2019).

cited by IWPs as the most persistent environmental hazard encountered at the site, more so because they are forced to frequently handle or sift through waste without the use of gloves or other personal protective equipment. Most IWPs, displaying scarred hands and feet, described injuries from glass as frequent occurrences that often required trips to the hospital or necessitated them missing periods of work to allow for healing (Figure 4). Another waste item around which problematisations have formed is old food, with some IWPs believing that consuming food waste found at Mzedi could cause illness ${ }^{29}$. However, this problematisation was not universally held, as many reported happily taking old food, either to eat at home or to feed to livestock. Similar problematisations have formed around medical waste, though few IWPs described encountering the needles and other sharps objects described by the maize growers, instead describing uncovering medicines, pills, and other chemicals, which they choose to avoid for the fear that they are poisonous or could otherwise cause sickness ${ }^{30}$. Finally, although not a waste item, the tractors, skip carriers, and dump trucks, either municipal or private, that are responsible for making the daily waste deliveries represented the most serious and visible danger to life and limb for Mzedi's IWPs. This danger stems from the tendency of some IWPs to wait near the entrance of the site for new deliveries, and when one arrives, climb on and ride on the back of the skip to its dumping point in order to have first pick of the waste (Figure 6). This behaviour has had unfortunate consequences however, as a number of IWPS have fallen from vehicles along the extremely rutted and uneven access road. According to the Dump Supervisor ${ }^{31}$, these falls most often result in a broken arm or leg, but for 


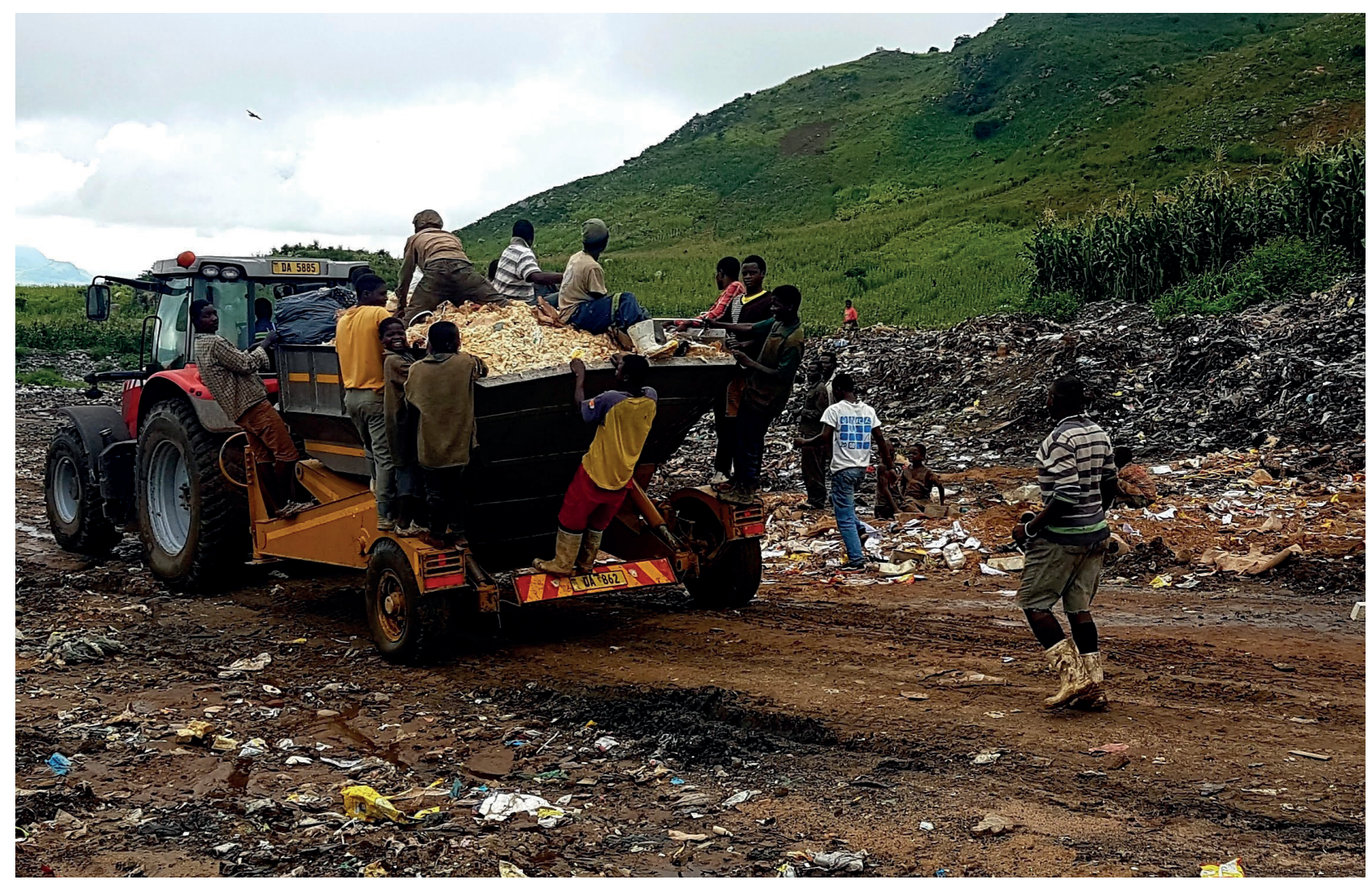

FIGURE 6: IWPs ride a new delivery into Mzedi (Kalina, 2019).

a few who have fallen under the wheels of the tractor, the result has been fatal. Although both sides regret the loss of life, there is a clear distinction in opinion in where the blame lies, with the city problematising the behaviour of the waste pickers as unsafe and reckless, while the IWPs criticise the city and the tractor drivers for not considering their safety or their livelihood needs ${ }^{32}$.

Although these dangers shape the ways in which IWPs problematise waste at Mzedi, the single largest factor influencing processes of problem formation within these individuals is their livelihoods-recovering value from what society has discarded. IWPs at Mzedi collect a broad range of materials, with most individuals specialising in a few specific waste streams, while a few prefer to collect more broadly or opportunistically. Commonly collected waste items include: recyclable metals, such as aluminium and copper, which are gathered and resold to scrap dealers ${ }^{33}$; plastic drink bottles which are either reused at a household level or sold to individuals who use them for storing resalable portions of cooking oil or other liquids ${ }^{34}$; scrap paper and wood which is sold as fuel ${ }^{35}$; plastic bags and other scrap plastics which are sold in bulk to commercial buyers or at a smaller scale for use as fire starters ${ }^{36}$; paint cans which are sold for the scrap metal content as well as for any leftover paint ${ }^{37}$; food waste which is used domestically as pig feed ${ }^{38}$; and glass: Carlsberg Beer or Coca-Cola bottles which carry deposits and are collected to be returned ${ }^{39}$. Although the range of items collected are diverse, the motivations driving each individual IWP's collections are consistent: they collect what they are able to sell. If there is a market for it, there is an IWP at Mzedi collecting it. There are a few waste items, however, that IWPs universally avoid; specific examples include most glass waste, chemicals, and some organic waste such as grass and sugar cane chaff. These items are not avoided because they are dangerous, though in some instances they certainly can be, but because, to the IWPs they are worthless. Carlsberg or Coca-Cola bottles can, and do, cause cuts just the same as an empty Heineken bottle or a broken windowpane, however they are not problematised in the same way as these other glass items are because they carry deposits and thus have value to the IWP. Likewise, the recovery of scrap metal can also often be hazardous and the IWPs suffer just as, if not more severely from the fires needed to recover the metals as the local maize growers. However, these items are also not problematised by IWPs at Mzedi in the same way as other environmental hazards because they are among the highest value recyclable items; the kind of waste they would like to see more of in Mzedi, certainly not as a problem that needs to be addressed.

Stemming from this dynamic of only problematising items with no resale value, IWPs had a tendency to speak in terms of a dichotomy of 'good' waste vs 'bad' waste. Akin to Kennedy's (2007) distinction between 'waste' and 'trash', 'good' waste represents items that have value, something that can be sold to support a livelihood, while 'bad' waste was worthless, had no value, and occupied time and space which could be spent more productively. This concept of waste being 'bad' was the principle factor shaping 
processes of problem formation for IWPs within Mze$\mathrm{di}$, and although safety considerations were considered within individual problematisations, value and livelihoods remained the overriding concern. Finally, this dichotomy ultimately influenced the way in which they problematise Mzedi itself. Although individuals conveyed concern about the physical deterioration of the site, these concerns were ancillary to a growing expression of alarm that the quality and quantity of recyclable materials reaching the site has decreased in recent years, as the quote at the start of this article indicated. As such, a number of respondents were left questioning the sustainability of their already precarious livelihoods, but, nonetheless, seem resigned to continue a life of quotidian hardships and problems in Mzedi.

\section{CONCLUSIONS}

The purpose of this article has been to explore how and why certain 'waste' items are and become understood as problems. It adopts Foucault's (1984) notion of 'problematisation' as an analytical lens for conceptualising processes of problem formation, through the eyes of two different groups scraping together livelihoods within and on the margins of Mzedi Dump Site: subsistence maize growers and informal waste pickers. The example of Mzedi, and the challenging lives of the individuals who live and work there, illustrate that problems do not exist independently from the people they affect, rather they are continually made and remade through human practice.

Of the countless pieces of detritus at Mzedi, the refuse of the small minority in Blantyre who have access to waste management services, what 'waste' objects or other environmental hazards have these individuals come to understand as problems, and how and why have those problematisations formed? For both maize growers and IWPS, problematisations are dynamic, driven by daily routine and personal hardship. Problematisations are shaped by the tangible: the visible, and often painful impacts that Mzedi's hazards have on their lives and livelihoods. For instance, both groups have clearly characterised glass and other sharp pieces of waste as problems, because these objects can harm them, and they have evidence: the poorly healed cuts and thick scars. Likewise, maize growers have problematised the persistent smoke that hangs over the site on the basis that it makes it hard to breath, causes coughing, and exacerbates illnesses. These are real hardships that they struggle with on a daily basis, which have crystalised their internalised processes of problem formation. Conversely, other 'waste' hazards such as the potential health risks associated with consuming dumpsite-grown maize have not been problematised because they are more intangible. As we have argued, this is not because growers cannot conceptualised linkages between 'waste' and their maize, but rather because the problem is distant, less visible, and more nebulous, and has not yet manifested in a way that has been seen or understood as a problem by growers. Finally, at Mzedi, the need to earn a living, and the consequences of falling short, is the most tangible reality of daily existence, and this dynamic has in turn shaped how individuals, and the IWPs in particular, problematise the hazards posed by the various waste items found there. 'Good' waste, is internalised based on its value. No matter how sharp or toxic the object may be, it is not problematised, rather it is desired and fought over because someone will buy it. It is not a problem, it is an opportunity. 'Bad' waste however, is not problematised because it is a hazard (it may be dangerous or innocuous), it is problematised because to the IWP it is has no value. Without a market or a willing buyer the item is considered useless, Kennedy's (2007) 'trash'; a problem taking up time and space which could be filled more profitably.

To Barnett and Bridge (2016), the value of Foucault's conceptualisation of problematisations lies in its ability to inform situational analysis of the formation of problems. Problematisations emerge from uncertainty or, occasionally, from distress or hardship. For Foucault (2001, p. 172) the problematisation is a response or 'answer' to something that is real: a concrete situation or a lived reality. Those working in and on the margins of Mzedi have problematised its waste for the tangible impacts it has on their lives. However, once these problematisations have formed, how have they affected how individuals navigate and react to the problems that they have identified? Unfortunately, in regards to Mzedi, clear and universal problematisations of certain waste objects, like broken glass, have not influenced behaviour or contributed to any collective action for change, as most individuals simply struggle to survive, and lack the agency and resources to pursue solutions. Nonetheless as Oberg (2019) reminds us, there remains value in bringing to light the full range of problematisations. Considering the full range of problematisations gives voice to previously disregarded problematisations, as well as the potentially marginalised groups forming them (Oberg, 2019). If the BCC does develop Mzedi in the future, the problematisations of these groups should be considered and acted upon, rather than being subordinated to the dominant problematisations championed by the City or privileged groups.

But once an object has been identified as a problem, what then? Many individuals would describe litter as a 'problem', but are generally happy to step over it on a busy city street, rather than take the time, to engage with it. Yet, at what point does 'trash' become something more than a nuisance that can be ignored, transforming into a problem that must be dealt with or actively avoided? How do these understandings of problems inform choice and individual processes of decision-making, particularly within the African city, many of which have lurched awkwardly into modernity, yet remain spaces of tremendous opportunity and imagination? These questions remain fertile space for further theoretical and empirical investigation.

\section{REFERENCES}

Ablitt, Jonathan, \& Smith, Robin James. (2019). Working out Douglas's aphorism: Discarded objects, categorisation practices, and moral inquiries. The Sociological Review, 67(4), 866-885. doi: $10.1177 / 0038026119854271$

Amusan, A.A., Ige, D.V., \& Olawale, R. (2005). Characteristics of Soils and Crops' Uptake of Metals in Municipal Waste Dump Sites in Nigeria. Journal of Human Ecology, 17(3), 161-175. 
Bacchi, Carol. (2009). Analysing Policy: What's the Problem Represented To Be?

Bacchi, Carol. (2012). Why Study Problematizations? Making Politics Visible. Open Journal of Political Science, 2, 1-8. doi: 10.4236/ ojps.2012.21001

Bacchi, Carol. (2015). The Turn to Problematization: Political Implications of Contrasting Interpretive and Poststructural Adaptations. Open Journal of Political Science, 5, 1-12. doi: 10.4236/ ojps.2015.51001

Bacchi, Carol. (2016). Problematizations in Health Policy:Questioning How "Problems" Are Constituted in Policies. SAGE Open, 6(2), 2158244016653986. doi: 10.1177/2158244016653986

Barnett, Clive, \& Bridge, Gary. (2016). The Situations of Urban Inquiry: Thinking Problematically about the City. 40(6), 1186-1204. doi: $10.1111 / 1468-2427.12452$

Davoudi, Simin. (2000). Sustainability: A new vision for the British planning system. Planning Perspectives, 15, 123-137. doi: $10.1080 / 026654300364056$

Davoudi, Simin. (2009). Scalar tensions in the governance of waste: the resilience of state spatial Keynesianism. Journal of Environmental Planning and Management, 52(2), 137-156. doi: 10.1080/09640560802666495

Denzin, Norman K., Lincoln, Yvonna S., MacLure, Maggie, Otterstad, Ann Merete, Torrance, Harry, Cannella, Gaile S., . . . McTier, Terrence. (2017). Critical Qualitative Methodologies. Reconceptualizations and Emergent Construction, 10(4), 482-498. doi: 10.1525/ irqr.2017.10.4.482

Douglas, M. (1966). Purity and Danger. London: Routledge.

Foucault, M. (1984). Polemics, Politics, and Problematizations: An Interview. In P. Rabinow (Ed.), The Foucault Reader. New York: Pantheon.

Foucault, M. (2001). Fearless Speech. New York: Semiotext(e).

Gregson, Nicky, \& Crang, Mike. (2010). Materiality and waste: Inorganic vitality in a networked world. Environment and Planning A, 42, 1026-1032. doi: 10.1068/a43176

Gutberlet, Jutta, \& Uddin, Sayed Mohammad Nazim. (2017). Household waste and health risks affecting waste pickers and the environment in low- and middle-income countries. International Journal of Occupational and Environmental Health, 23(4), 299310. doi: 10.1080/10773525.2018.1484996

Hillier, J. (2009). Assemblages of Justice: The 'Ghost Ships' of Graythorp. International Journal of Urban and Regional Research, 33(3), 640-661. doi: 10.1111/j.1468-2427.2009.00861.x

Hird, Myra J. (2012). Knowing Waste: Towards an Inhuman Epistemology. Social Epistemology, 26(3-4), 453-469. doi: 10.1080/02691728.2012.727195

Ka-Ming, W., \& Jieying, Z. (2019). Living with waste: Becoming "free" as waste pickers in Chinese cities. China Perspectives(2), 67-74.

Kalina, M., Tilley, E., Ali, F., Woodenberg, W., Reimers, B., \& Trois, C. (2019). Blurred Lines: Agricultural Production on the Margins of a Dumpsite in Blantyre, Malawi. Paper presented at the 17th International Waste Management and Landfill Symposium, Sardinia, Italy.

Kennedy, G. (2007). An Ontology of Trash: The Disposable and its Problematic Nature. Albany: State University of New York Press.

Kitchin, R., \& Tate, N.J. (2000). Conducting Research in Human Geography. New Jersey: Prentice Hall.
Li, Guangke, Chen, Junyan, Yan, Wei, \& Sang, Nan. (2017). A comparison of the toxicity of landfill leachate exposure at the seed soaking and germination stages on Zea mays L. (maize). Journal of Environmental Sciences, 55, 206-213.

Moore, Sarah A. (2012). Garbage matters:Concepts in new geographies of waste. Progress in Human Geography, 36(6), 780-799. doi: $10.1177 / 0309132512437077$

Ndau, H., \& Tilley, E. (2018). Willingness to Pay for Improved Household Solid Waste Collection in Blantyre, Malawi. Economies, 6(4), 54.

Oberg, Angela. (2019). Problematizing Urban Shit(ting): Representing Human Waste as a Problem. 43(2), 377-392. doi: 10.1111/14682427.12744

Okoronkwo, N.E., Igwe, J.C., \& Onwuchekwa, E.C. (2005). Risk and health implications of polluted soils for crop production. African Journal of Biotechnology, 4(13), 1521-1524.

Oloko, Patrick. (2018). Human waste/wasting humans: dirt, disposable bodies and power relations in Nigerian newspaper reports. Social Dynamics, 44(1), 55-68. doi: 10.1080/02533952.2018.1441111

Opaluwa, O.D., Aremu, M.O., Ogbo, L.O., Abiola, K.A., Odiba, I.E., Abubakar, M.M., \& Nweze, N.O. (2012). Heavy metal concentrations in soils, plant leaves and crops grown around dump sites in Lafia Metropolis, Nasarawa State, Nigeria. Advances in Applied Research, 3(2), 780-784.

Pastor, J., \& Hernández, A.J. (2012). Heavy metals, salts and organic residues in old solid urban waste landfills and surface waters in their discharge areas: Determinants for restoring their impact. Journal of Environmental Management, 95, 542-549.

Petts, Judith, \& Niemeyer, Simon. (2004). Health risk communication and amplification: learning from the MMR vaccination controversy. Health, Risk \& Society, 6(1), 7-23. doi: $10.1080 / 13698570410001678284$

Reno, Joshua. (2015). Waste and Waste Management. Annual Review of Anthropology, 44(1), 557-572. doi: 10.1146/annurevanthro-102214-014146

Reno, Joshua Ozias. (2014). Toward a New Theory of Waste: From 'Matter out of Place' to Signs of Life. Theory, Culture \& Society, 31(6), 3-27. doi: 10.1177/0263276413500999

Sang, Nan, Han, Ming, Li, Guangke, \& Huang, Mingzhu. (2010). Landfill leachate affects metabolic responses of Zea mays L. seedlings. Waste Management, 30, 856-862.

SOFET. (2016). Mzedi Water Analysis. Blantyre: Society for Friends of Environment and Technology.

Spelman, Elizabeth V. (2011). Combing Through the Trash: Philosophy Goes Rummaging. The Massachusetts Review, 52(2), 313-325.

Turnbull, Nick. (2006). How Should We Theorise Public Policy? Problem Solving and Problematicity. Policy and Society, 25(2), 3-22. doi: 10.1016/S1449-4035(06)70072-8

Van Bemmel, Alexis, \& Parizeau, Kate. (2019). Is it food or is it waste? The materiality and relational agency of food waste across the value chain. Journal of Cultural Economy, 1-14. doi: 10.1080/17530350.2019.1684339

Viney, W. (2014). Waste: A Philosophy of Things. London: Bloomsbury. Wang, B. (2019). Sacred Trash and Personhood: Living in Daily WasteManagement Infrastructures in the Eastern Himalayas. Cross-Currents: East Asian History and Culture Review, 30, 101-119.

\footnotetext{
${ }^{1}$ Informal Waste Picker \#17, 24/04/2019.

2 Throughout our own analysis we try to maintain Kennedy's distinction between 'waste' and 'trash', though often the distinction does not translate neatly from the original Chichewa, so we occasionally resort to interpreting the intent of the respondents.

${ }^{3}$ Serving as an online hub for scholars, activists, environmentalists, and other communities engaged in waste, Discard Studies provides a platform for critical and informed discussion around the relationships between waste and society, contextualised within broader sociocultural-economic analysis. Their monthly compilation 'The Dirt' seeks to assemble recent articles, job postings, and calls for participation relevant within the discipline.

${ }^{4}$ The purpose has not been to provide a complete survey, rather to highlight pieces that have been particularly useful to the author during the conceptualisation of this study.

${ }^{5}$ Mzedi is owned by the Blantyre City Council (BCC) through the Department of Planning and Estate Management Services, while the site is operated by the Department of Health and Social Services

${ }^{6}$ Dr. Kanjunjunju (04/23/2019).
}

7 The Malawi Bureau of Standards specifications for safe drinking water require a maximum Pb concentration of $50 \mu \mathrm{g} / \mathrm{L}$. According to SOFET (2016), ground water testing in Moto Village revealed $\mathrm{Pb}$ concentrations exceeding $715 \mu \mathrm{g} / \mathrm{L}$. Unfortunately, potentially harmful metals such as $\mathrm{As}, \mathrm{Co}, \mathrm{Fe}, \mathrm{Ni}$, or $\mathrm{Zn}$ were not analysed.

${ }^{8}$ This could partially be due to lack of maintenance and the resultant physical deterioration of the berm over the past decade. Across its breadth the berm has severely eroded, failing in a number of spots, spilling solid waste in the water below.

${ }^{9}$ Dump Supervisor (04/24/2019)

${ }^{10}$ Dr. Kanjunjunju (04/23/2019).

11 Dump Supervisor $(04 / 24 / 2019)$

${ }^{12}$ Dump Supervisor (04/24/2019),

${ }^{13}$ Representatives from the City induced the director of the Department of Health and Social Services and the manager of Mzedi Dumpsite.

${ }^{14}$ Excluding those with City officials, which were conducted in English.

${ }^{15}$ The study was approved by the National Committee on Research in the Social Sciences and Humanities (NCRSH) of Malawi; Protocol NO. P.03/19/356. ${ }^{16}$ Translator $(27 / 05 / 2019)$ 
${ }^{17}$ Maize Grower \#6, (04/24/2019).

${ }_{18}$ Maize Grower \#1 (04/24/2019), Translator (27/05/2019).

${ }^{19}$ Many of the interviews conducted with growers for this study were done while the respondent was processing their maize harvest within their homes.

${ }^{20}$ Alternatively, some households dry the maize on the cob, store it, and strip it prior to use.

${ }^{21}$ Maize Grower \#2 (04/24/2019), Maize Grower \#4 (04/24/2019), Maize Grower \#5 (04/24/2019), Maize Grower \#6, (04/24/2019).

${ }^{22}$ According to Kalina et al. (2019), the principle danger in consuming maize from contaminated spaces, like a dumpsite, would be its ability to bio-accumulate potentially harmful heavy metals, such as arsenic (As) and copper $(\mathrm{Cu})$. The consumption of potentially toxic quantities of As poses the greatest, and most likely, risk given the context. At a biochemical level, As (arsenic) acts to coagulate proteins, inhibiting the production of adenosin triphosphate (ATP), which is essential in metabolic processes (Okoronkwo et al, 2005). Furthermore, although concentrations may remain low, the potential for bioaccumulation, and the ability for soil contamination to increase over time, suggests that the risk of exposure to heavy metals due to plant uptake renders the use of contaminated soils, such as those present at dumpsites, risky spaces for agricultural production (see (Amusan et al. 2005; Li et al., 2017; Okoronkwo et al., 2005; Opaluwa et al., 2012; Pastor \& Hernández, 2012; Sang et al., 2010)).

${ }^{23}$ A parastatal entity, which buys and sells maize in order to regulate prices and relieve shortages.

${ }^{24}$ Maize Grower \#1 (04/24/2019), Maize Grower \#4 (04/24/2019), Maize Grower \#5, (04/24/2019).
${ }^{25}$ Maize Grower \#2 (04/24/2019).

${ }^{26}$ Maize Grower \#4 (04/24/2019), Maize Grower \#6 (04/24/2019).

${ }^{27}$ Maize Grower \#4 (04/24/2019).

${ }^{28}$ According to Kalina et al. (2019), at Mzedi, many who used fertilizers sporadically reported not being able to differentiate between fertilised and non-fertilised plots, while those who could not afford fertiliser at all still described positive harvests.

${ }^{29}$ Informal Waster Picker \#10 (04/24/2019), Informal Waster Picker \#12 $(04 / 24 / 2019)$

30 Informal Waster Picker \#2 (04/24/2019), Informal Waster Picker \#6 (04/24/2019), Informal Waster Picker \#15 (04/24/2019), Informal Waster Picker \#17 (04/24/2019).

${ }^{31}$ Dump Supervisor (04/24/2019),

${ }^{32}$ Dr. Kanjunjunju (04/23/2019), Dump Supervisor (04/24/2019),

33 Informal Waster Picker \#1 (04/24/2019), Informal Waster Picker \#5 (04/24/2019), Informal Waster Picker \#7 (04/24/2019), Informal Waster Picker \#9 (04/24/2019), Informal Waster Picker \#16 (04/24/2019).

34 Informal Waster Picker \#10 (04/24/2019), Informal Waster Picker \#12 (04/24/2019), Informal Waster Picker \#13 (04/24/2019)

35 Informal Waster Picker \#2 (04/24/2019), Informal Waster Picker \#3 (04/24/2019), Informal Waster Picker \#11 (04/24/2019).

${ }^{36}$ Informal Waster Picker \#3 (04/24/2019), Informal Waster Picker \#8 (04/24/2019), Informal Waster Picker \#11 (04/24/2019).

${ }^{37}$ Informal Waster Picker \#17 (04/24/2019).

${ }^{38}$ Informal Waster Picker \#6 (04/24/2019).

${ }^{39}$ Informal Waster Picker \#5 (04/24/2019), Informal Waster Picker \#18 $(04 / 24 / 2019)$ 